\title{
Early Warming Stress on Juvenile Fish Impairs Testicular Development and Sperm Quality But Contrastingly Elicits Intergenerational Thermotolerance
}

\author{
Arno Juliano Butzge \\ Sao Paulo State University \\ Tulio Teruo Yoshinaga \\ Sao Paulo University \\ Omar David Moreno Acosta \\ Instituto Tecnológico de Chascomús \\ Juan Ignacio Fernandino \\ Instituto Tecnológico de Chascomús \\ Eduardo Antônio Sanches \\ Sao Paulo State University \\ Yara Aiko Tabata \\ Instituto de Pesca \\ Claudio Oliveira \\ Sao Paulo State University \\ Ricardo Shohei Hattori ( $\nabla$ hattori.fish@gmail.com ) \\ Instituto de Pesca
}

\section{Research Article}

Keywords: Salmonids, germ cell, thermal adaptation, quiescent gonad, global warming

Posted Date: February 4th, 2021

DOI: https://doi.org/10.21203/rs.3.rs-156005/v1

License: (c) (i) This work is licensed under a Creative Commons Attribution 4.0 International License. Read Full License 
1 Early warming stress on juvenile fish impairs testicular development and sperm quality but 2 contrastingly elicits intergenerational thermotolerance

3 Arno Juliano Butzge ${ }^{1}$, Tulio Teruo Yoshinaga ${ }^{2}$, Omar David Moreno Acosta ${ }^{3}$, Juan Ignacio Fernandino ${ }^{3}$, Eduardo

4 Antônio Sanches ${ }^{4}$, Yara Aiko Tabata ${ }^{5}$, Claudio de Oliveira ${ }^{1}$, Ricardo Shohei Hattori ${ }^{5 *}$

5 1: Department of Structural and Functional Biology, Botucatu São Paulo State University (UNESP), Institute of

6 Biosciences, Botucatu, São Paulo 18618-689, Brazil;

7 2: Department of Surgery, School of Veterinary Medicine and Animal Sciences, University of São Paulo, São Paulo,

8 São Paulo 05508-270, Brazil

9 3: Laboratorio de Biología del Desarrollo, Instituto Tecnológico de Chascomús (INTECH), Consejo Nacional de 10 Investigaciones Científicas y Técnicas/Universidad Nacional de San Martín (CONICET/UNSAM). Chascomús,

117130 , Argentina

12 4: Fishery Engineering Course and Aquaculture Centre (CAUNESP) São Paulo State University, Registro, São Paulo

13 11900-000, Brazil

14 5: Salmonid Experimental Station at Campos do Jordão, UPD-CJ, Sao Paulo Fisheries Institute (APTA/SAA),

15 Campos do Jordão, São Paulo 12460-000, Brazil

16

17 Corresponding Author:

18 * Ricardo Shohei Hattori, UPD-CJ Sao Paulo Fisheries Institute (APTA/SAA), CP 361. 12460-000. Campos do 19 Jordao, Brazil. +55 123663-1021

20 E-mail: hattori.fish@gmail.com 
The exposure of adult fish to warm or high temperatures is known to impair reproduction, yet the long-term reproductive impacts for treatments at early life are not well clarified. This study aimed to evaluate the effects of 25 warm temperature (WT) during juvenile stage on gonad maturation, gamete quality, and offspring thermotolerance in rainbow trout. While the comparison of basic reproductive parameters in WT females did not reveal any kind of impairment, many WT males showed an atrophied, undeveloped gonad, or a smaller testis with lower milt volume; sperm quality parameters in WT males and deformity rates in the respective progeny were also highly affected. However, despite of such negative effects, many of the remaining progenies presented better rates of survival and growth when exposed to the same conditions as those of parental fish (WT), suggesting that thermal stress in parr stage males elicited intergenerational thermoresistance after a single generation. The present results support that prolonged warming stress during early life stages can adversely affect key reproductive aspects, but constrastingly increase offspring performance at upper thermal ranges. These findings have implications on the capacity of fish to adapt and to cope with global warming.

Keywords: Salmonids, germ cell, thermal adaptation, quiescent gonad, global warming

\section{Main Text}

\section{Introduction}

Water temperature comprises an important modulatory factor with critical roles on fish reproduction.

42 During early life stages, the destiny of gonadal sex differentiation in gonochoristic species can be irreversibly driven

43 towards either female or male by temperature, overcoming the predisposed sex determined by genotypic factors ${ }^{1-4}$.

44 The appearance of sex-reversed fish and the concomitant skews in sex ratios has great implications from ecological perspectives due to their impacts on population structure ${ }^{5}$.

Another effect of temperature on reproduction occurs through the regulation of reproductive cycle, either by

47 promoting ${ }^{6}$ or suppressing gametogenesis ${ }^{7}$. However, chronic exposure at those temperatures or acute thermal stress

48 at even higher temperatures can cause opposite inhibitory effects on spermatogenesis ${ }^{8,9}$. In ovaries, although warm

49 conditions are also able to hasten gametogenesis as in males ${ }^{6}$, high temperatures that do show clear inhibitory effects

50 on spermatogenesis do not necessarily induce comparable changes in oocyte development ${ }^{10}$. At sub-lethal, high

51 temperature conditions, the survival of testicular somatic-supporting cells as well as the germ cells can be severely

52 affected, whereby undifferentiated spermatogonia seems to be more tolerant to depletion by apoptosis than the

53 differentiated ones, such as spermatocytes, spermatids, and spermatozoa ${ }^{8,9}$. The mechanism of heat-induced germ

54 cell depletion is not well understood, but the Sertoli cells are likely involved, since apoptosis in these cells have been

55 detected along with germ cells ${ }^{8,9}$. On the other hand, undifferentiated oogonia seems to be more susceptible than the 
differentiated oocytes upon exposure to those temperatures ${ }^{10}$, suggesting that high temperatures affect fish reproduction in a sex-specific manner.

Although the effects of thermal stress on fish reproduction have been assessed in some species, the implications on their reproductive capacity have not been well explored, especially in terms of gamete quality and offspring performance. Furthermore, the performance of offspring produced by fish exposed to warm water temperature has not been well evaluated yet. Research about how temperature acts on fish germ line, on gametes production or quality, and on progenies fitness might provide important insights for the evaluation of environmental changes (e.g., global warming) on wild populations and extensive aquaculture. On this regards, salmonids are an excellent group of fish to evaluate the effects of increasing temperature because they include several cold-water species which born in freshwater environments and then migrate downward to the river mouths until reaching the sea. Also, some species present variants that spend their entire life cycle in inland waters (landlocked) such as the rainbow trout (Oncorhynchus mykiss) and the Atlantic salmon (Salmo salar). But regardless of these different life cycles, salmonids have a high likelihood to experience warm temperatures and hypoxia conditions during the juvenile stage ${ }^{11,12}$. Some of those effects include impairment of steroidogenesis and vitellogenin synthesis ${ }^{13}$, and advance or delay in oocyte maturation in females ${ }^{14}$. In case of males, impairment of spermatogenesis and reduced milt volume are reported in fish exposed to high temperature ${ }^{15}$. treatment at warm temperatures during juvenile stage on several reproduction parameters in female and male adults. We also compared survival and growth performances of the respective progenies under warm temperature in juveniles and the upper thermal tolerance in adults in order to investigate the intergenerational inheritance of thermotolerance.

\section{Results}

Effects of warm temperature on body growth and gonads of juveniles

At the end of the experiment ( 3 months) with F0 juvenile fish, warm temperature group (WT) showed lower

82 survival rate than control group (CT) (70\% and 97\%, respectively), but growth parameters such as standard length

83 (mean $\pm \mathrm{SD}=21.67 \pm 9.41 \mathrm{~cm}$ and $23.57 \pm 8.76 \mathrm{~cm}$, respectively), and body weight $(81.61 \pm 28.79 \mathrm{~g}$ and $71.73 \pm$

$8418.26 \mathrm{~g}$, respectively) did not differ significantly (Fig. 1A-B). The gonadosomatic index in females was lower in WT

85 compared to CT $(0.0007 \pm 0.0003$ vs $0.0012 ; p<0.05)$ whereas no difference was found for males (Fig. 1C).

86 Histological analyses of ovaries (Fig. 1D and 1F) and testis (Fig. 1E and 1G) did not reveal clear differences between

87 WT and CT groups.

\section{Reproductive parameters of adults}

Females from WT group were significantly smaller than those from CT group and presented higher condition factor (K). Nevertheless, no differences were found in body weight (Suppl. Fig. 1). Fecundity rates, oocyte 
mean weight, and the percentage of non-ovulated females did not differ between females of WT and CT group (Suppl. Fig. 2; Table 1).

WT males were significant smaller and had lower body weight than control males; hence, condition factor was significantly higher in WT group (Suppl. Fig. 1), as in females. Gonad dissection and histological analyses in some of those fish revealed three patterns of testis morphology. The first one consisted in a large whitish testis, similar to those of CT males (Fig. 2A). In the second pattern, a smaller whitish testis was detected and correlated with males with low relative milt volume (Fig. 2C). The third pattern was found for immature males and consisted in a thinner gonad with a reddish color (Fig. 2E). Histological analyses revealed the presence of some undifferentiated spermatogonia and a high quantity of spermatozoa in the first two patterns (Fig. 2B and 2D) whereas the third pattern was characterized by undifferentiated spermatogonia without any spermatozoa or spermatocytes (Fig. $2 \mathrm{~F}$ and $2 \mathrm{H}$ ), as revealed by immunohistochemistry analysis with an antibody for undifferentiated spermatogonia (Fig. 2G), which resembled the immature testis of F0 juveniles (Fig. 1E).

The relative milt volume was also lower in WT than CT group (Fig. 3A), with no difference in the concentration of spermatozoa (Fig. 3B). The estimated total amount of spermatozoa was reduced in about $57 \%$ in WT males (Fig. 3C). A proportion of males did not show secondary sexual characters and did not release any milt. These males were classified as immature males and they were not detected in any of CT males (Table 1). The morphological analysis of the sperm showed a 1.5-fold higher the percentage of abnormal cells in WT compared to CT group (59.99\% and 39.56\%, respectively) (Fig. 3D and 3E).

Computer analysis of sperm motility showed no differences for all parameters among 5 and $15 \mathrm{~s}$, but at $20 \mathrm{~s}$ velocity was higher while wobble was lower in WT compared to CT males (Fig. 3F). At both 25 and 30 s, sperm motility was detected in $66.67 \%$ and $33.33 \%$ of CT males, respectively (Fig. 3G), whereas in WT group, no male showed sperm motility in any of these time points.

\section{Fertilization, hatching, and abnormality rates in offspring from WT and CT broodstock}

The comparative analysis of fertilization and hatching rates in crosses between CT females vs. CT males,

117 CT females $v s$. WT males, and WT females $v s$. CT males showed no statistic differences for those parameters (Fig.

118 4A). Although the rate of abnormal fish also showed no statistic differences, the average values in the progenies derived from CT females $v s$. WT males were almost twice higher compared to other crosses (Fig. 4A).

\section{Comparison of survival, growth, and thermal tolerance of F1 juveniles derived from WT and CT males} except for WT1. Regarding growth parameters, both standard length and body weight values were significantly similar or higher in WT in relation CT groups (Fig. 4B); in the trial 3, which recorded the highest average temperature $\left(19.2 \pm 1.29^{\circ} \mathrm{C}\right)$, both WT5 and WT6, showed higher body weight values than respective CT groups. In the upper temperature tolerance test at $28^{\circ} \mathrm{C}, \mathrm{F} 1$ sub-adults and adults from WT group presented a significant 
127 superior effective time (ET), as demonstrated by the comparison between de survival curves (Fig. $4 \mathrm{C}$ ). The $\mathrm{LD}_{50}$

128 values were $71.4 \%$ and $54.5 \%$ higher in WT group for sub-adult and adults, respectively.

\section{Discussion}

In this study, we demonstrated that exposure to warm temperature in male juveniles affect negatively not only survival, growth, and fecundity, but also the motility of spermatozoa and body formation in the respective progenies. Despite of those impacts, the progenies obtained from these males presented a remarkable high survival and growth rates when exposed to warm temperature compared to the control group, which supports an increased thermal tolerance after a single generation.

Long-term exposure to temperatures above optimal ranges causes detrimental effects on growth and survival in salmonids ${ }^{14,16}$. Another related impact comprises the depletion of the germ cells in juveniles and adults of many other fish species $9,10,17,18$. In our experiment, heat treatment at juvenile stage did not affect reproductive parameters in

139 females, which was not the case of males. Those fishes showed quiescent gonads that persisted for two consecutive

140 reproductive seasons, and reduced testes, impacts that were not observed in any fish from CT group and, to the best

141 of our knowledge, in any teleost fish. Since the quiescent gonads possess germ cells, we can consider these fish as

142 infertile, but not sterile. A deep analysis on the regulatory mechanisms is required to determine how this state is

143 controlled, if these fish still possess the capacity to resume spermatogenesis, or if steroid hormones can make this

144 fish to overcome such "quiescent" condition. The significant decrease in milt volume is likely due to spermatogonial

145 apoptosis ${ }^{9,10,18,19}$, because thermal treatment was performed at juvenile stage, when the immature testes are composed

146 mainly by undifferentiated spermatogonia. Regarding the difference in heat sensitivity between females and males,

147 similar responses have been reported in teleost and mammals ${ }^{10,20,21}$, supporting the idea that spermatogonia exhibits

148 higher heat-sensitivity than the oogonia.

149 Another intriguing effect of heat treatment was observed on motility parameters of spermatozoa, whereby

150 WT group did not show any motility after $20 \mathrm{~s} \mathrm{(25} \mathrm{and} 30 \mathrm{~s}$ ). In addition, WT spermatozoa also had higher sperm

151 velocity and lower wobble compared to CT group at $20 \mathrm{~s}$. Such patterns could be associated with high energy

152 consumption by WT spermatozoa at the initial 5 and $10 \mathrm{~s}$, based on average motility which was about 19 to $26 \%$

153 higher, respectively. Thus, after 20s, WT spermatozoa would have lower available energy for motility. Reduced

154 sperm motility after chronic heat treatment has been reported in fish and mammals ${ }^{22,23}$. In these cases, while thermal

155 exposure encompassed mature adult males in which the spermatogenesis is under course, in our experiment, heat

156 treatment was performed only during the pre-pubertal period. Therefore, the effects of temperature on spermatogonia

157 persisted for about 18 months up to spermatozoa differentiation, affecting motility parameters, which suggest that

158 warm temperature can compromise permanently the germ cells; in mammals, motility parameters were restored after

159 a recovery period ${ }^{22}$. Those constitutive impacts observed in this study could be related to the particular thermal

160 conditions during pre-pubertal developmental stage, which is characterized by high mitotic proliferation of

161 spermatogonia ${ }^{24}$. 

dividing cells are more prone to errors in DNA under stress conditions ${ }^{25}$. Thus, spermatogonia might have acquired mutations that would be deleterious for proper development of embryos. On this regard, the analysis of sperm morphology revealed that the WT group had a higher percentage of abnormal gametes when compared to the CT group. Although we do not have evidence that deformed embryos were indeed generated by those abnormal spermatozoa, studies in mice have suggested that certain types of morphologically abnormal sperm with defects in head formation are associated with a higher frequency of chromosomal mutations ${ }^{26,27}$. Thus, the abnormal sperm morphology due to deleterious mutations in DNA of spermatogonia could account for higher embryo malformations in WT males-derived progenies.

171 In spite of many negative effects on reproductive parameters of F0 males, the juveniles of the respective

172 progenies (F1) presented remarkable superior survival and growth performances when exposed to the same

173 conditions as those of parental fish. Moreover, sub-adults and adults progenies showed longer effective time under

174 sublethal temperature, supporting improved thermotolerance of F1 generation. These data may imply that warm

175 temperature may have selected the F0 fish with genotypes that confer better thermal tolerance (WT group showed

176 higher mortality), similarly to the reports of thermo-tolerant rainbow trout generated after several generations, as

177 described both in the wild ${ }^{28}$ and captivity ${ }^{29}$. Alternatively, beneficial mutations may have been inserted into

178 spermatogonia's genome or, considering the fast acquisition of thermal tolerance, epigenetic modifications

179 (methylation or non-coding RNAs) may have been "imprinted" onto spermatogonia in response to thermal stress and 180 those "signatures" would be carried by spermatozoa DNA to F1 progeny. Moreover, the survival rates in the first 181 trial did not differ between WT and CT males, which was caused by the appearance of white spot disease. However, 182 in the second and third trials, WT males presented survival rates above $87 \%$ and superior growth rates compared to

183 CT group, suggesting that chronic thermal exposure during juvenile stage may cause long-term effects on

184 spermatozoa and on respective progenies. Whether such tolerance is brought about by simple selection of genotypes with high tolerance or as mentioned previously, by epigenetic modifications in the germ cell genome or transcriptome has to be further explored, but regardless of the mechanism, our results open a new perspective on the capacity of organisms to overcome long-term stressful conditions within a short-term scale. Although the final quantity of gametes and viable progenies can be severely reduced upon thermal stress, the remaining ones are able to acquire genotypes or epigenotypes that confer higher thermal tolerance into existing populations or even to replace completely these populations, thus establishing new populations.

In conclusion, this study showed that warm temperature exposure in juveniles causes deleterious effects on germ cells that persist even in adults by affecting gamete production in males. Apart from germ cell degeneration, germ cell quiescence or functional sterility has to be considered as another new impact of thermal stress in fish with impairment on reproductive capacity. Nevertheless, these negative effects may be counteracted by improved survival and growth performances of progenies at warm temperature, suggesting a clear tradeoff between parental fecundity and offspring thermal resistance. These results have implications on the adaptive capacity of wild populations to cope with chronic thermal stress associated to global climate change $\mathrm{e}^{30,31}$. 


\section{Materials and Methods}

All experiments were conducted following the protocols approved by the Sao Paulo Fisheries Institute under the CEEAIP 07/2018. The procedures for the care and use of experimental fish were also approved by the

202 institution's committee under the same CEEAIP 07/2018. This study was carried out in compliance with the ARRIVE guidelines.

\section{Fish rearing conditions.}

This study was conducted at the governmental research hatchery Salmonid Experimental Station (SES) and in a commercial trout farm, respectively located at neighboring Campos do Jordão and Pindamonhangaba municipalities, Sao Paulo State, Brazil with a distance of $10.7 \mathrm{~km}$ between sites. These two sites were chosen with the aim to provide a similar water source and at conditions that approximate to those of natural environments. The hatchery (control water) is supplied by a stream running at the top of the Mantiqueira mountain at $1520 \mathrm{~m}$ above mean sea level (AMSL), while the farm (warm water) is supplied by a stream descending abruptly to the base of that mountain at $715 \mathrm{~m}$ (AMSL); both streams run through rainforest on governmental protected areas.

F0 fish used in this experiment were produced and maintained at SES until the beginning of experiment. 6-

214 months-old parr stage juveniles (body weight $22.62 \pm 8.94 \mathrm{~g}$; standard length $10.08 \pm 1.38 \mathrm{~cm}$; mean $\pm \mathrm{SD}$ ) were

215 divided in two groups (100 per group), whereby the group transferred to the trout farm corresponded to warm

216 temperature (WT) group $\left(19.22 \pm 1.65^{\circ} \mathrm{C}\right.$; mean $\left.\pm \mathrm{SD}\right)$ and the one maintained at SES was the control temperature

217 (CT) group $\left(14.74 \pm 1.63{ }^{\circ} \mathrm{C}\right.$; mean $\left.\pm \mathrm{SD}\right)$. The decision on applying thermal manipulation in juveniles instead of

218 larvae or adults was based on the higher likelihood of warm or high temperatures exposure at this stage, which

219 coincides with summer, as wild salmonids born in headwaters and generally migrate downward to the sea during this season. Juveniles from both experimental groups were reared in $0.25 \mathrm{~m}^{3}$ round tanks during 90 days with constant water flow under natural photoperiod conditions. After this period, all animals were individually tagged (30 in WT

222 and 36 in CT group) and transferred to a single $2 \mathrm{~m}^{3}$ round tank at SES for an additional period of 15 months, when

223 most of fish reached sexual maturity. Gonad samples were collected during juvenile and adult stages for histological

224 analyses (see scheme in Fig. 5). Animals were fed commercial diet (45\% protein) twice a day ad libitum during the

225 entire experiment.

\section{Histological analysis of juvenile and adult gonads.}

Both juvenile and adult fish were sacrificed with an overdose of benzocaine $(0.2 \mathrm{~g} / \mathrm{L})$. Gonad samples were dissected, fixed in Bouin's solution overnight at room temperature, and stored in ethanol $70 \%$ until further processing. Samples were dehydrated in ascending ethanol series, embedded in paraffin, sectioned transversally at 5 $\mu \mathrm{m}$ thickness, and stained with hematoxylin-eosin (HE). For immunohistochemistry analysis sections were

232 deparaffined, re-hydrated, and submitted to antigen retrieval with citrate buffer (pH 6.0) in microwave for 10 min.

233 Endogenous peroxidase activity was blocked using $3 \% \mathrm{H}_{2} \mathrm{O}_{2}$ solution in $0.1 \mathrm{M}$ PBS at room temperature during 30 
min. Sections were rinsed in 0.1M PBS and blocked with horse serum from ImmPRESS Universal reagent (Vector Laboratories). Sections were incubated with the primary antibody \#189, specific for undifferentiated spermatogonia (1:500 dilution $)^{32}$, during $16 \mathrm{~h}$ at $4{ }^{\circ} \mathrm{C}$, rinsed in 0.1M PBS, and incubated with ImmPRESS Universal secondary antibody (Vector Laboratories) during $30 \mathrm{~min}$ at RT. Then, sections were rinsed in 0.1M PBS, incubated with ImmPACT DAB HRP substrate (Vector Laboratories), counter-stained with hematoxylin and mounted.

\section{Analysis of growth and reproductive parameters in two-years-old fish.}

Total body weight $(\mathrm{BW} ; \mathrm{g})$ and standard length $(\mathrm{SL} ; \mathrm{cm})$ were measured for each fish. The condition factor $\mathrm{K}$ was calculated as $\mathrm{K}=100 \times \mathrm{BW} / \mathrm{SL}^{3}$ and the gonad weight $(\mathrm{GW}$; $)$ was also measured for some fish to calculate the gonad-somatic index (GSI=GW/BWx100). Reproductive parameters were weekly screening by gentle abdominal pressure for ovulated females and spermiating males. Fish were anesthetized in benzocaine solution and the maximum quantity/volume of gametes were collected. This process was repeated every week only for males and for this reason the milt volume measurement was performed more than once in some fish, with the highest values considered as the milt volume for each male. Spermatozoa concentration was measured in a Neubauer chamber. For females, the total weight of ovulated oocytes and mean oocyte weight were counted. Those parameters were used to calculate the relative fecundity, which in females was presented as the oocyte number per gram of fish whereas in males it was presented as the milt volume in $\mathrm{mL}$ per $\mathrm{g}$ of fish.

The milt was diluted in buffered formaldehyde in the proportion of 1:1000 (milt: diluent solution) for spermatozoa morphological analysis. Samples were stained with Rose Bengal dye (3\%) and analyzed under the microscope ${ }^{33}$. A total of 200 spermatozoa per male $(n=6$ for each group in duplicate) were randomly selected and scored as "normal" or "abnormal", based on ovoid or triangular head shape, respectively ${ }^{34}$.

\section{Computer analysis of sperm motility.}

The activation process for fresh milt was performed using $1 \mu \mathrm{L}$ of milt and $400 \mu \mathrm{L}$ of $0.01 \% \mathrm{NaHCO}_{3}$ $\left(25^{\circ} \mathrm{C}, 0.0\right.$ mOsm.kg-1), as activator solution. Six spermiating-males for each of WT and CT groups were randomly selected. Images and videos were captured as described in previous studies ${ }^{35-37}$ and processed following the description of the components required for CASA application through a free software ${ }^{35}$, with settings adapted from Lahnsteiner, F., Mansour, N. \& Plaetzer, K, 2010 ${ }^{38}$. Spermatozoa that presented curvilinear velocity (VCL), average path velocity (VAP), velocity in straight line (VSL), above 20, 10, and $3 \mu \mathrm{m} \mathrm{s}-1$, respectively, were considered as motile. Besides those parameters the motility rate (MOT), straightness (STR), wobble (WOB), and progression (PROG) were also measured. Those analyses were performed for $1 \mathrm{~s}$ (100 images) at different post-activation times $(5,10,15,20,25$, and $30 \mathrm{~s})$, with three videos for each male.

\section{Evaluation of fertilization, hatching, and abnormality rates in progenies.}

In the analysis using 2 years-old-fish, a total of 12 WT males were crossed with $13 \mathrm{CT}$ females and conversely 6 WT females were crossed with 11 CT males. For those crosses, $27 \mathrm{~g}$ of oocytes were inseminated with 
$2 \mathrm{~mL}$ of milt. In the following year, three-years-old males from WT $(\mathrm{n}=8)$ and CT $(\mathrm{n}=12)$ were crossed with eggs from a single CT female, in order to evaluate whether the effects observed in progenies from two-years-old-fish were restricted to fish from that age. Spermatozoa were activated using a sodium bicarbonate solution $(0.01 \%)$. Eggs were then hydrated with rearing water during $20 \mathrm{~min}$. and incubated at $11{ }^{\circ} \mathrm{C}$ in UV-treated water under constant flow, following conditions described in a previous study ${ }^{39}$. The percentage of fertilization at eyed-egg stage, hatching rate, and abnormality in eleuteroembryos were quantified for each cross. Embryos with body deformations such as twisted body or with circular movements were considered as abnormal.

\section{Survival and growth performance of progenies derived from WT males.}

The survival and growth performances of F1 progenies derived from WT males were compared with those from CT males. Milt from 2 WT males and 2 CT males was used to artificially inseminate the same pool of oocytes for each trial. Egg incubation and larvae rearing followed the same procedure described in the previous section. For challenge experiments under warm temperature, 300 fingerlings were randomly selected per cross. This procedure was repeated in the second trial and third trial, with $2 \mathrm{WT}$ and $2 \mathrm{CT}$ males each. Fish were transferred to the same commercial trout farm at Pindamonhangaba and maintained for 3 months at the same rearing conditions used for thermal treatment in broodstock fish. The temperatures in the first, second, and third trials were $17.92 \pm 1.57^{\circ} \mathrm{C}$, $18.74 \pm 1.59^{\circ} \mathrm{C}$, and $19.20 \pm 1.29^{\circ} \mathrm{C}$ (mean $\pm \mathrm{SD}$ ) at the same rearing conditions as those of WT F0 males.

\section{Analysis of upper temperature tolerance}

Upper temperature tolerance was compared between CT and WT groups using 1-year-old sexually immature fish ( $\mathrm{n}=32$ per group; $\mathrm{BW} \pm \mathrm{SD}=305.8 \pm 48.9 \mathrm{~g}$ and $295.5 \pm 39.3 \mathrm{~g}$, respectively) and 2 years-old maturing females ( $\mathrm{n}=15$ per group; $\mathrm{BW} \pm \mathrm{SD}=952 \pm 184.8 \mathrm{~g}$ and $801.3 \pm 295.1 \mathrm{~g}$, respectively) from $\mathrm{F} 1$ generation. Fish were transferred into the temperature trial tank 24 hours prior to the beginning of the experiment for acclimation. Temperature was raised from ambient $\left(16-17^{\circ} \mathrm{C}\right)$ to upper lethal temperature of $28^{\circ} \mathrm{C}$, following the methodology described by Jackson et al. $1998^{40}$. Water flow was held constant and dissolved oxygen levels were maintained at a minimum of $8.0 \mathrm{mg} / \mathrm{L}$. The time when fish started to lose the capacity to maintain the equilibrium was recorded for all individuals and considered as the 'effective time' (ET) in the zone of thermal resistance. $\mathrm{LT}_{50}$ (median lethal temperature) was calculated for each curve.

\section{Sex genotyping by $s d Y$ amplification}

Total genomic DNA was extracted from caudal fin using saline buffer method ${ }^{41}$ and used for PCR amplification of $s d Y$ gene (sexually dimorphic on the $\mathrm{Y}$ chromosome). Primers and amplification conditions followed $^{42}$ and PCR products were electrophoresed in 1\% agarose gel stained with Ethidium bromide.

\section{Statistical analysis}



GSI in juveniles and spermatozoa parameters were compared by the t-student test. The comparison of effective time was performed by a survival test, with the curves compared based on Gehan-Breslow-Wilcoxon test. Differences were considered as significant for $p \leq 0.05$.

\section{References}

312 1. Hattori, R. S., Strüssmann, C. A., Fernandino, J. I. \& Somoza, G. M. Genotypic sex determination in teleosts: 313 insights from the testis-determining amhy gene. Gen. Comp. Endocrinol. 192, 55-9 (2013).

314 2. Piferrer, F. Endocrine sex control strategies for the feminization of teleost fish. Aquaculture 197, 229-281 (2001).

3. Struussmann, C. A., Moriyama, S., Hanke, E. F., Cota, J. C. C. \& Takashima, F. Evidence of thermolabile sex

4. Fernandino, J. I., Hattori, R. S., Moreno Acosta, O. D., Strüssmann, C. A. \& Somoza, G. M. Environmental stress-induced testis differentiation: androgen as a by-product of cortisol inactivation. Gen. Comp. Endocrinol.

5. Fernandino, J. I. \& Hattori, R. S. Sex determination in neotropical fish: Implications ranging from aquaculture

6. De Alvarenga, É. R. \& De França, L. R. Effects of different temperatures on testis structure and function, with emphasis on somatic cells, in sexually mature Nile tilapias (Oreochromis niloticus). Biol. Reprod. 80, 537-

7. Schulz, R. W. et al. Spermatogenesis in fish. Gen. Comp. Endocrinol. 165, 390-411 (2010).

8. Ito, L. S., Takahashi, C., Yamashita, M. \& Strüssmann, C. A. Warm water induces apoptosis, gonadal degeneration, and germ cell loss in subadult pejerrey Odontesthes bonariensis (Pisces, Atheriniformes). Physiol. Biochem. Zool. 81, 762-74 (2008).

9. Nóbrega, R. H. et al. Spermatogonial stem cell niche and spermatogonial stem cell transplantation in zebrafish. PLoS One 5, 1-16 (2010). wild specimens. Physiol. Biochem. Zool. 81, 775-784 (2008). 
11. Davies, B. \& Bromage, N. The effects of fluctuating seasonal and constant water temperatures on the photoperiodic advancement of reproduction in female rainbow trout, Oncorhynchus mykiss. Aquaculture 205, 183-200 (2002).

12. Stehfest, K. M., Carter, C. G., McAllister, J. D., Ross, J. D. \& Semmens, J. M. Response of Atlantic salmon Salmo salar to temperature and dissolved oxygen extremes established using animal-borne environmental sensors. Sci. Rep. 7, 4545 (2017).

13. King, H. R. \& Pankhurst, N. W. Ovarian growth and plasma sex steroid and vitellogenin profiles during vitellogenesis in Tasmanian female Atlantic salmon (Salmo salar). Aquaculture 219, 797-813 (2003).

14. Pankhurst, N. W., King, H. R., Crichigno, S. A. \& Cussac, V. E. Temperature and salmonid reproduction: Implications for aquaculture. J. Fish Biol. 76, 69-85 (2010).

15. Billard, R. \& Breton, B. Sensibilité à la température des différentes étapes de la reproduction chez la truite arcen-ciel. Cah. du Lab. d'Hydrobiologie Montereau 5, 5-24 (1977).

16. Myrick, C. A. \& Cech Jr, J. J. Temperature effects on juvenile anadromous salmonids in California's central valley: what don’t we know? Rev. Fish Biol. Fish. 14, 113-123 (2004).

17. Majhi, S. K., Hattori, R. S., Yokota, M., Watanabe, S. \& Strüssmann, C. A. Germ cell transplantation using sexually competent fish: An approach for rapid propagation of endangered and valuable germlines. PLoS One 4, e6132 (2009).

18. Nakamura, M. et al. Sexual characteristics of high-temperature sterilized male Mozambique tilapia, Oreochromis mossambicus. Zool. Lett. 1, 21 (2015).

19. Majhi, S. K., Hattori, R. S., Rahman, S. M., Suzuki, T. \& Strüssmann, C. A. Experimentally induced depletion of germ cells in sub-adult Patagonian pejerrey (Odontesthes hatcheri). Theriogenology 71, 1162-1172 (2009).

20. Paul, C., Teng, S. \& Saunders, P. T. K. A single, mild, transient scrotal heat stress causes hypoxia and oxidative stress in mouse testes, which induces germ cell death. Biol. Reprod. 80, 913-919 (2009).

21. Hansen, P. J. Effects of heat stress on mammalian reproduction. Philos. Trans. R. Soc. B Biol. Sci. 364, 33413350 (2009).

22. Houston, B. J. et al. Heat exposure induces oxidative stress and DNA damage in the male germ line†. Biol. Reprod. 98, 593-606 (2018).

Breckels, R. D. \& Neff, B. D. The effects of elevated temperature on the sexual traits, immunology and survivorship of a tropical ectotherm. J. Exp. Biol. 216, 2658-2664 (2013). 
24. Loir, M. Spermatogonia of rainbow trout: I. Morphological characterization, mitotic activity, and survival in primary cultures of testicular cells. Mol. Reprod. Dev. 53, 422-33 (1999).

25. Pérez-Crespo, M., Pintado, B. \& Gutiérrez-Adán, A. Scrotal heat stress effects on sperm viability, sperm DNA integrity, and the offspring sex ratio in mice. Mol. Reprod. Dev. 75, 40-47 (2008).

26. Kishikawa, H., Tateno, H. \& Yanagimachi, R. Chromosome analysis of BALB/c mouse spermatozoa with normal and abnormal head morphology. Biol. Reprod. 61, 809-812 (1999).

27. Sun, F., Ko, E. \& Martin, R. H. Is there a relationship between sperm chromosome abnormalities and sperm morphology? Reproductive Biology and Endocrinology vol. 41 (2006).

28. Crichigno, S. A. \& Cussac, V. E. Rainbow trout (Oncorhynchus mykiss) adaptation to a warmer climate: the performance of an improved strain under farm conditions. Aquac. Int. 27, 1869-1882 (2019).

29. Ineno, T. et al. Thermal tolerance of a thermally selected strain of rainbow trout Oncorhynchus mykiss and the pedigrees of its F1 and F2 generations indicated by their critical thermal maxima. Fish. Sci. 84, 671-679 (2018).

30. Ficke, A. D., Myrick, C. A. \& Hansen, L. J. Potential impacts of global climate change on freshwater fisheries. Rev. Fish Biol. Fish. 17, 581-613 (2007).

31. Peterson, T. C., Stott, P. A. \& Herring, S. Explaining extreme events of 2011 from a climate perspective. Bull. Am. Meteorol. Soc. 93, 1041-1067 (2012).

32. Hayashi, M. et al. Establishment of novel monoclonal antibodies for identification of type A spermatogonia in teleosts†े. Biol. Reprod. (2019) doi:10.1093/biolre/ioz080.

33. Silva Pinheiro, J. P., Bertacini de Assis, C., Sanches, E. A. \& Moreira, R. G. Aluminum, at an environmental concentration, associated with acidic $\mathrm{pH}$ and high water temperature, causes impairment of sperm quality in the freshwater teleost Astyanax altiparanae (Teleostei: Characidae). Environ. Pollut. 262, 114252 (2020).

34. Billard, R. Ultrastructure of trout spermatozoa: Changes after dilution and deep-freezing. Cell Tissue Res. 228, 205-218 (1983).

35. Wilson-Leedy, J. G. \& Ingermann, R. L. Development of a novel CASA system based on open source software for characterization of zebrafish sperm motility parameters. Theriogenology 67, 661-672 (2007).

36. Sanches, E. A. et al. Sperm motility of Rhamdia quelen studied using computer-assisted analysis by opensource software. Aquac. Res. 42, 153-156 (2010).

37. Sanches, E. A. et al. Sperm motility parameters for Steindachneridion parahybae based on open-source 
software. J. Appl. Ichthyol. 29, 1114-1122 (2013).

393

401

403

404

405

406

407

408

409

410

411

412

413

414

415

416

417

418

419

420

421

38. Lahnsteiner, F., Mansour, N. \& Plaetzer, K. Antioxidant systems of brown trout (Salmo trutta f. fario) semen. Anim. Reprod. Sci. 119, 314-321 (2010).

39. Hattori, R. S. et al. Generation of a white-albino phenotype from cobalt blue and yellow-albino trouts: inheritance pattern and chromatophores analysis. bioRxiv 570861 (2019) doi:10.1101/570861.

40. Jackson, T. R. et al. Identification of two QTL influencing upper temperature tolerance in three rainbow trout (Oncorhynchus mykiss) half-sib families. Heredity (Edinb). 80, 143-151 (1998).

41. Aljanabi, S. M. \& Martinez, I. Universal and rapid salt-extraction of high quality genomic DNA for PCRbased techniques. Nucleic Acids Res. 25, 4692-3 (1997).

42. Yano, A. et al. An immune-related gene evolved into the master sex-determining gene in rainbow trout, Oncorhynchus mykiss. Curr. Biol. 22, 1423-1428 (2012).

\section{Acknowledgments}

The authors thank L.R.S., A.D.S., and R.A.S.L. for technical assistance on fish rearing and maintenance and A.K.P. from Sítio Forelle for providing fish rearing facilities in thermal manipulation experiments.

\section{Author Contributions}

Conceived and designed the experiments: RSH, YAT, CO, AJB. Performed the experiments: RSH, YAT, AJB, TTY, ODMA, EAS. Analyzed the data: RSH, AJB, TTY, JIF, EAS. Wrote the paper: RSH, AJB, TTY. Reviewed the manuscript for content: RSH, JIF, CO.

\section{Competing interests.}

The authors declare no competing interests.

\section{Funding}

This work was funded by FAPESP (Processo 2013/17612-9 to R.S.H and Processo 2019/29050-2 to A.J.B), CAPES, CONICET-FAPESP International Cooperation Grant D 2979/16 (to J.I.F. and R.S.H.). CO received financial support from Conselho Nacional de Desenvolvimento Científico e Tecnológico - CNPq proc. 306054/2006-0. 


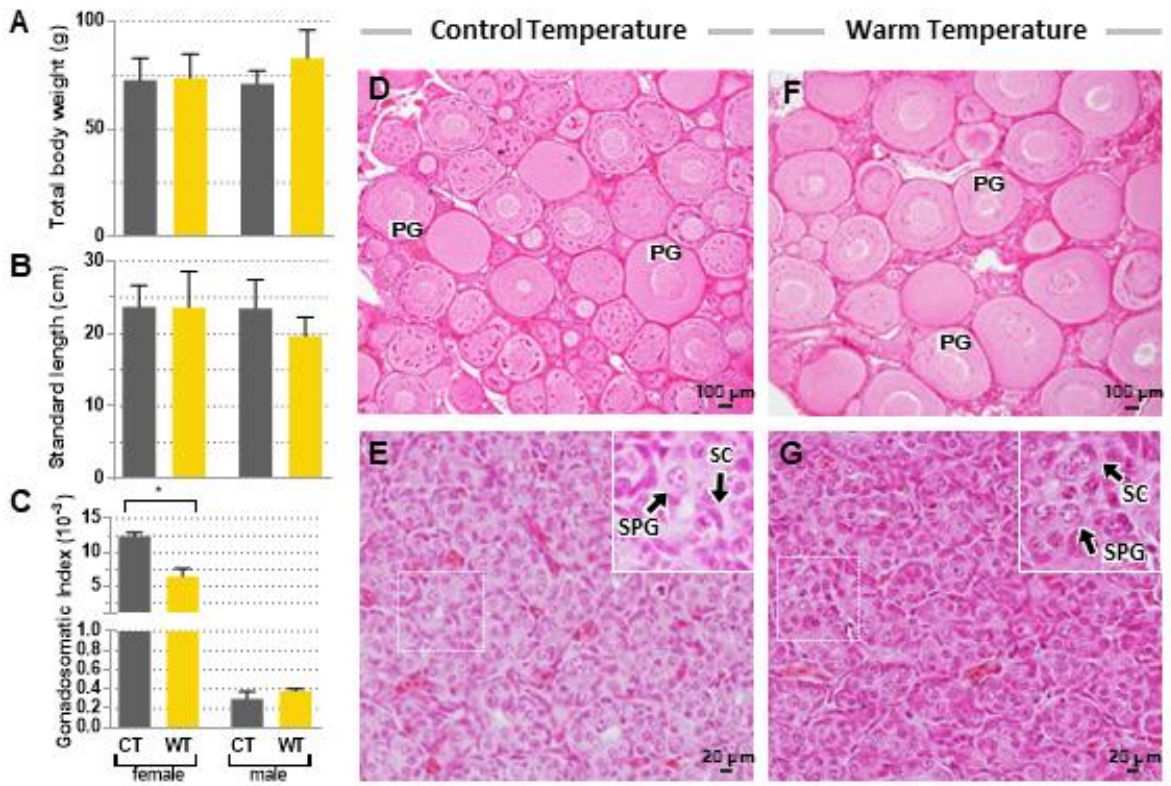

Figure 1. Growth and reproductive parameters of F0 juveniles from control and warm temperature groups.

427 (A) Total body weight, (B) standard length, and (C) gonadosomatic index in females and males after thermal

428 treatment. (D and $\mathbf{F})$ Ovary and ( $\mathbf{E}$ and $\mathbf{G})$ testis histology from F0 juvenile fish three months after thermal

429 treatment. The enlarged images in E and G refer to the respective dotted boxes. PG: primary growth oocytes; SPG:

430 spermatogonia; CS: Sertoli cells 

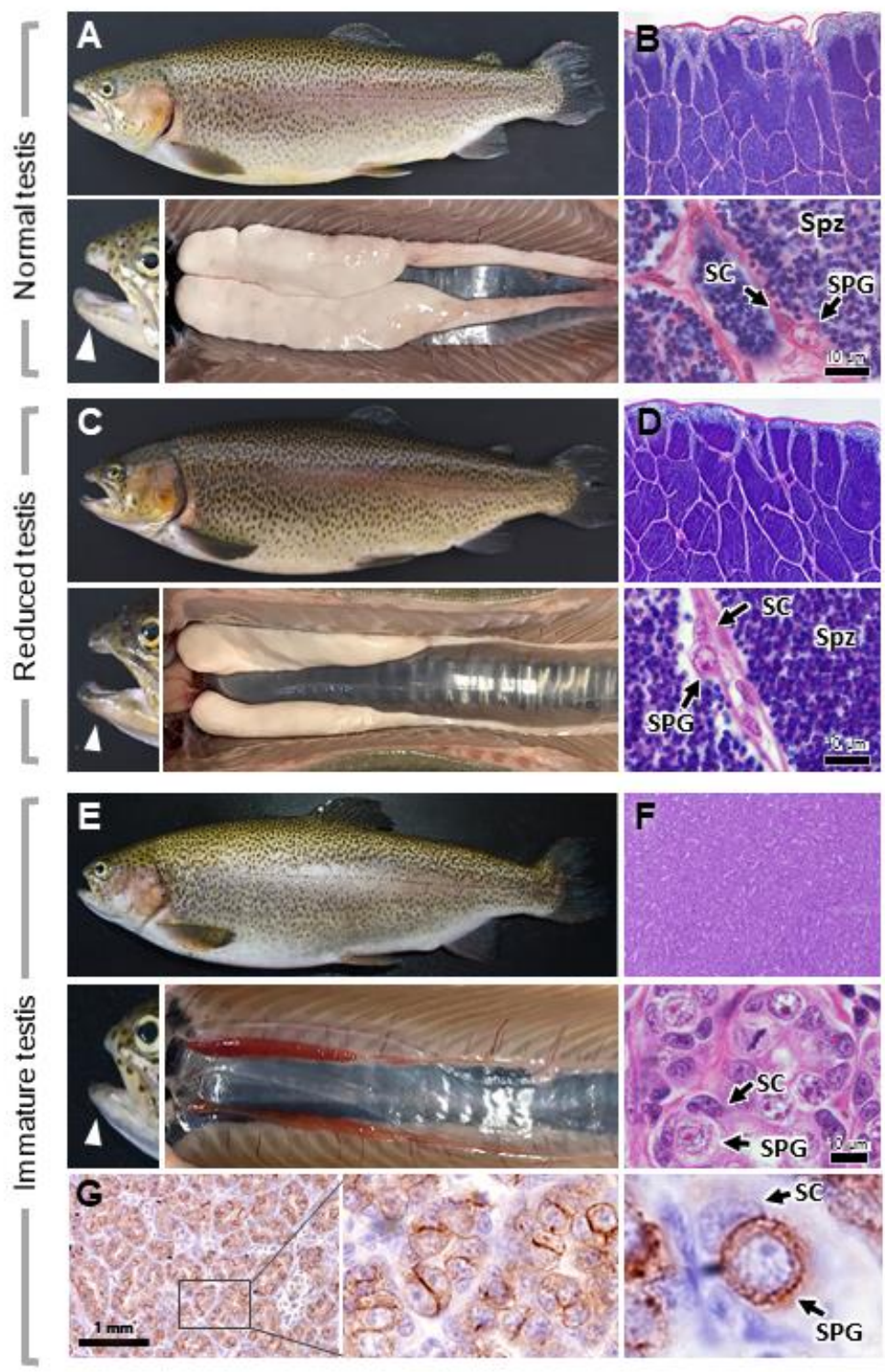

Figure 2. External body appearance and morpho-histological analysis of gonads in warm and control temperature males. (A-B) Adult trout with typical male phenotype presenting a hook-like jaw, a large whitish testis 435 with abundant spermatozoa; spermatogonia and Sertoli cells are also present. (C-D) Adult trout with typical male 436 phenotype as in (A), but with a smaller testis; testis histology presents similar aspect to (B). (E, F) Adult trout 437 without male-specific secondary sexual characteristics, presenting a thin, reddish gonad, without spermatozoa; most germ cells are spermatogonia. SPG: spermatogonia; CS: Sertoli cells; Spz: spermatozoa. Arrowheads indicate the 439 jaw, which has a hook-like morphology in $\mathbf{A}$ and $\mathbf{C}$ (mature males), but not in $\mathbf{E}$ (immature male). (G)

440 Immunohistochemical detection of undifferentiated spermatogonia in immature testis with a cell surface marker. 
A

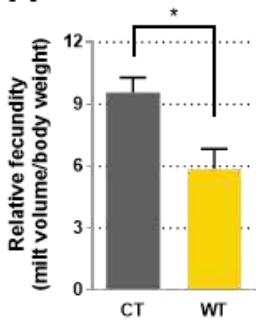

D

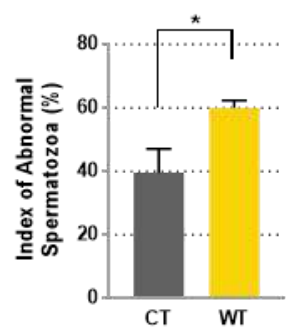

F

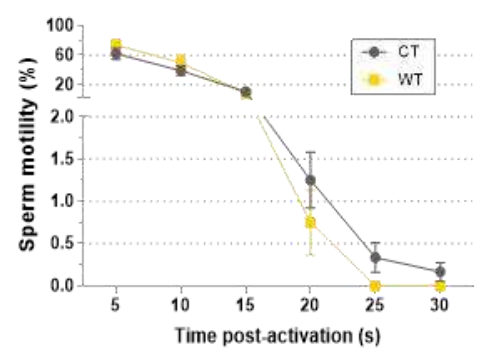

E
C
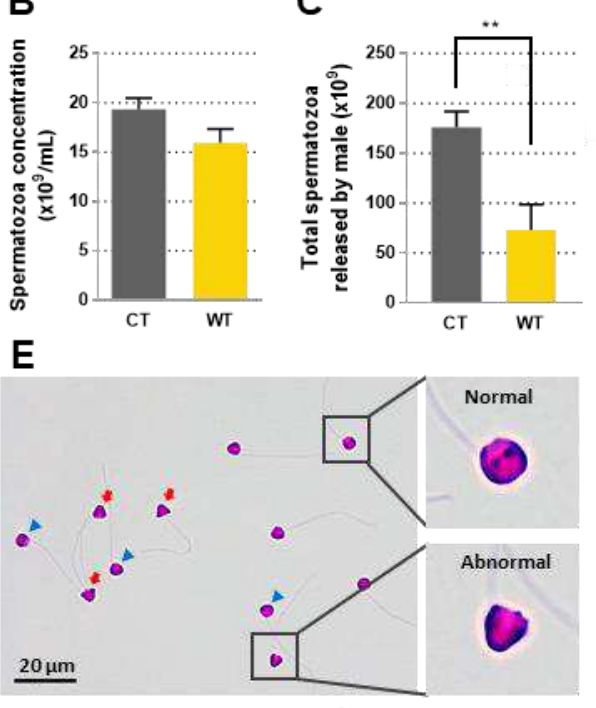

G

$20 \mathrm{~s}$

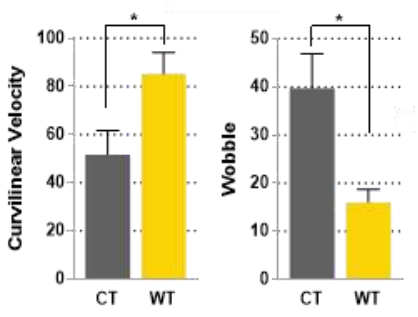

Figure 3. Fecundity of males and sperm motility parameters in control (CT) and warm (WT) temperature groups. (A) The relative fecundity was significantly lower in WT than in CT group, (B) but without differences in sperm concentration, (C) the total number of sperm released per male was significantly lower in the WT than in CT.

(D-E) Morphological comparison between the percentages of spermatozoa with normal-ovoid and abnormal-

triangular heads. (F) Sperm motility analyses in CT and WT males between 5 and 30 s post-activation. (G)

Curvilinear velocity and wobble showed opposite patterns at $20 \mathrm{~s}$. Asterisks indicate significant difference for $p<$ 0.05 . 

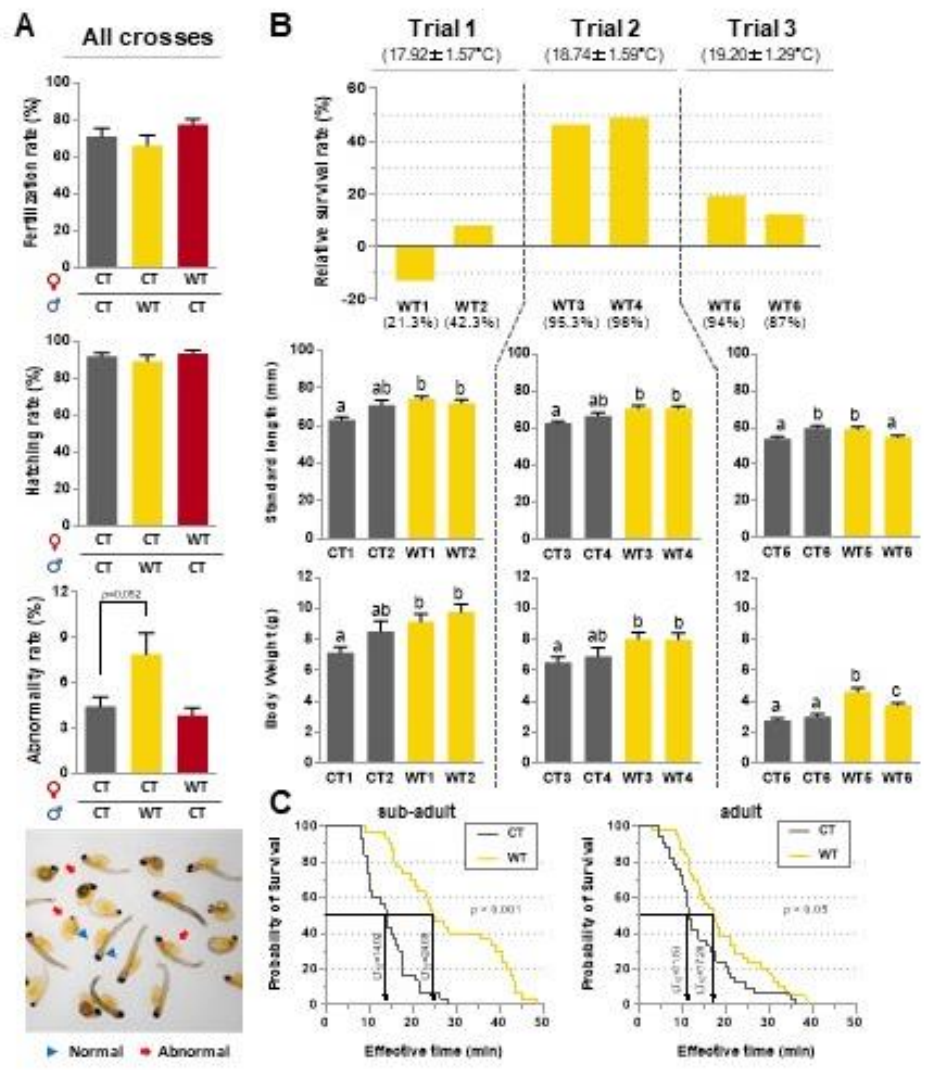

Figure 4. Fertilization, hatching, and abnormality rates of progeny produced by gametes from control (CT) and warm temperature (WT) groups (A). Rates of fertilization, hatching, and abnormality did not differ among the crosses. Crosses between CT females vs. WT males showed higher abnormality rates, with typical body deformities showed in the image just below. (B) Normalized survival rate (in relation to the average of respective CT groups) and growth parameters in F1 progeny derived from the CT/WT males submitted to warm temperature. Temperature values below each trial represent the average temperature \pm SD during challenge experiment. Numbers between brackets in the graph of survival represent the absolute survival rates for each group. (C) Comparative analysis of upper thermal tolerance using F1 sub-adults and adults from CT and WT males using effective time (ET). LT $_{50}$ (median lethal temperature) values are indicated for each curve. 


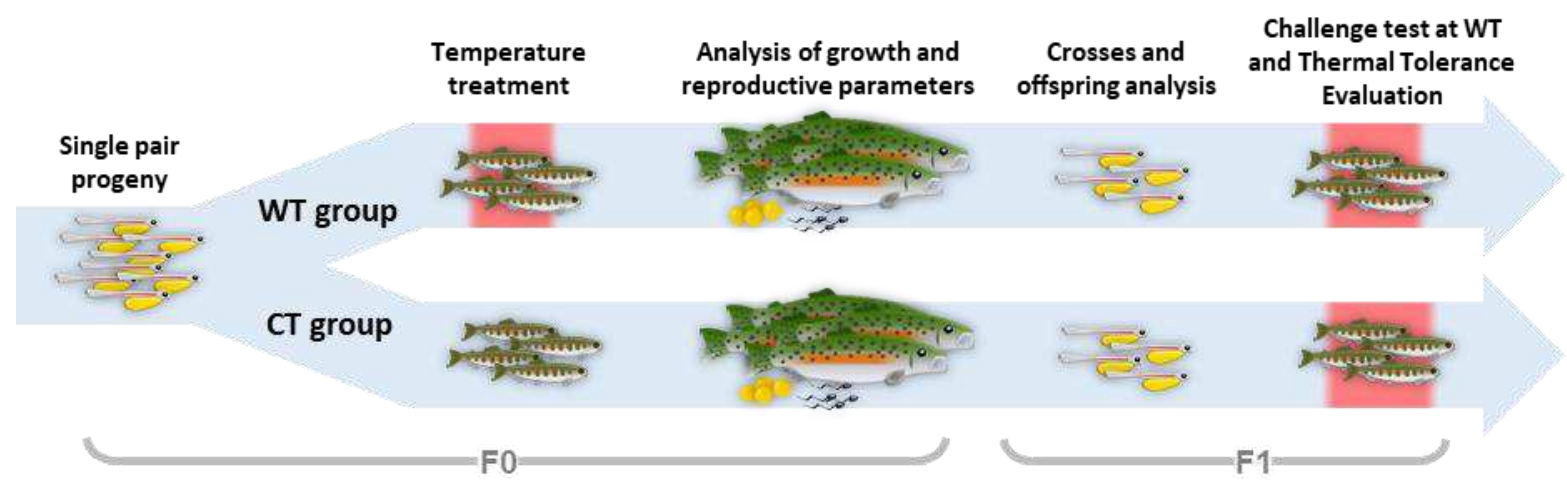

Figure 5. Overview representation of the experimental design. Rainbow trout juveniles obtained from a

464 single pair cross were divided in two groups. At six-months, one group was exposed to warm temperature (WT) for

465 three months in a local fish farm (Pindamonhangaba) while control group was maintained at Salmonid Experimental

466 Station (Campos do Jordao). After this period, the treated group returned to control temperature until reaching sexual

467 maturity for the analysis of growth and reproductive parameters. Finally, survival and growth performance of

468 respective progenies at WT and upper thermal tolerance were evaluated.

469 
471 Table 1. Number of mature and immature adult fish at both control (CT) and warm temperature groups 16 mo after 472 treatment. Number in parentheses represent the frequency of animals in each group.

\begin{tabular}{lllll}
\hline Maturity & \multicolumn{2}{l}{ Females } & \multicolumn{2}{l}{ Males } \\
\cline { 2 - 5 } Stage & WT & CT & WT* & CT \\
\hline Matures & 6 & 13 & 12 & 17 \\
Immatures & $(75 \%)$ & $(81.25 \%)$ & $(60 \%)$ & $(100 \%)$ \\
& 2 & 3 & 8 & 0 \\
& $(25 \%)$ & $(18.75 \%)$ & $(40 \%)$ & $(0 \%)$
\end{tabular}

$473 *$ Represent significant difference for Fisher's test considering $p<0.05$. 


\section{Figures}

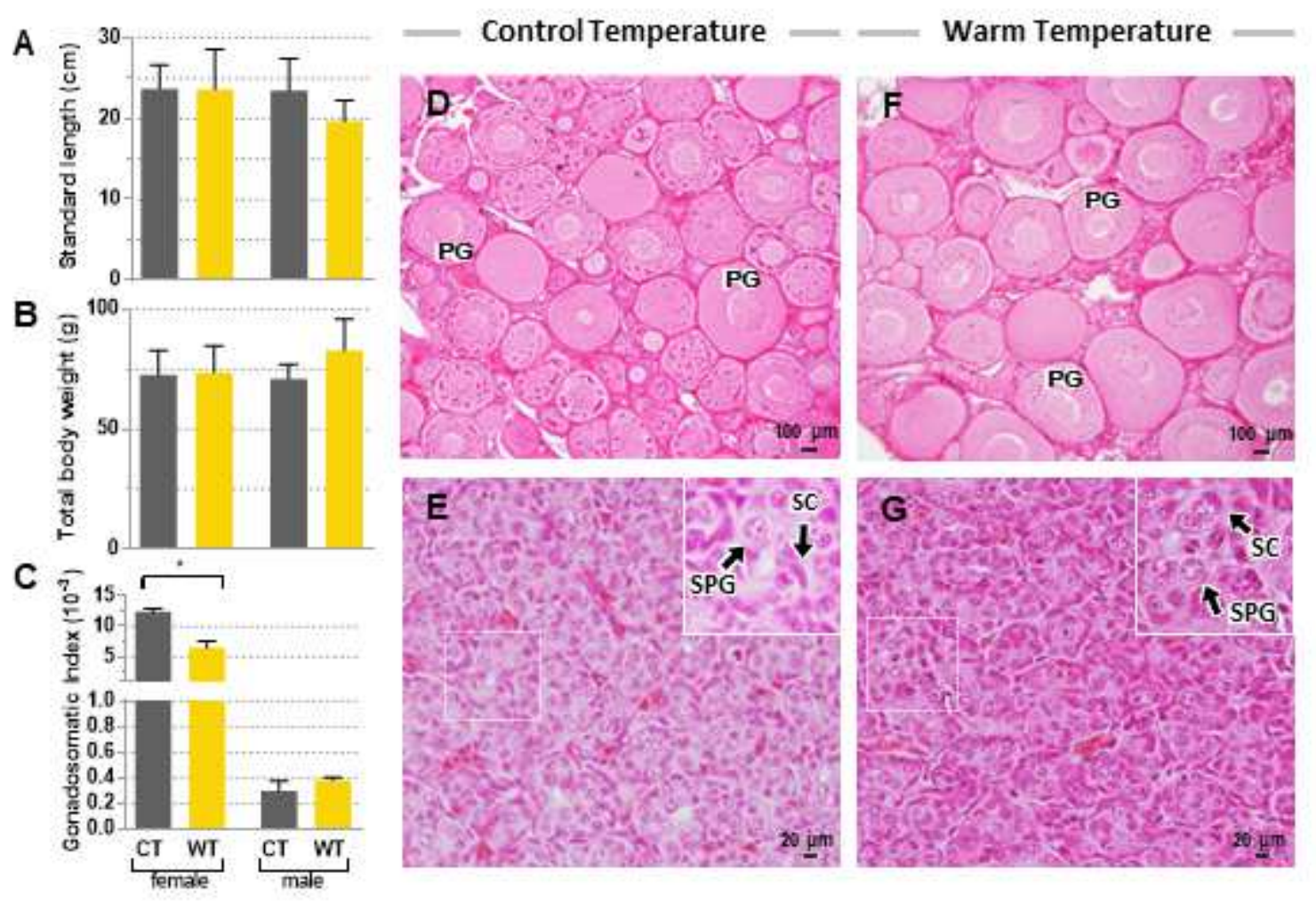

Figure 1

Growth and reproductive parameters of F0 juveniles from control and warm temperature groups. (A) Total body weight, (B) standard length, and (C) gonadosomatic index in females and males after thermal treatment. (D and F) Ovary and (E and $G$ ) testis histology from F0 juvenile fish three months after thermal treatment. The enlarged images in $\mathrm{E}$ and $\mathrm{G}$ refer to the respective dotted boxes. PG: primary growth oocytes; SPG: spermatogonia; CS: Sertoli cells 

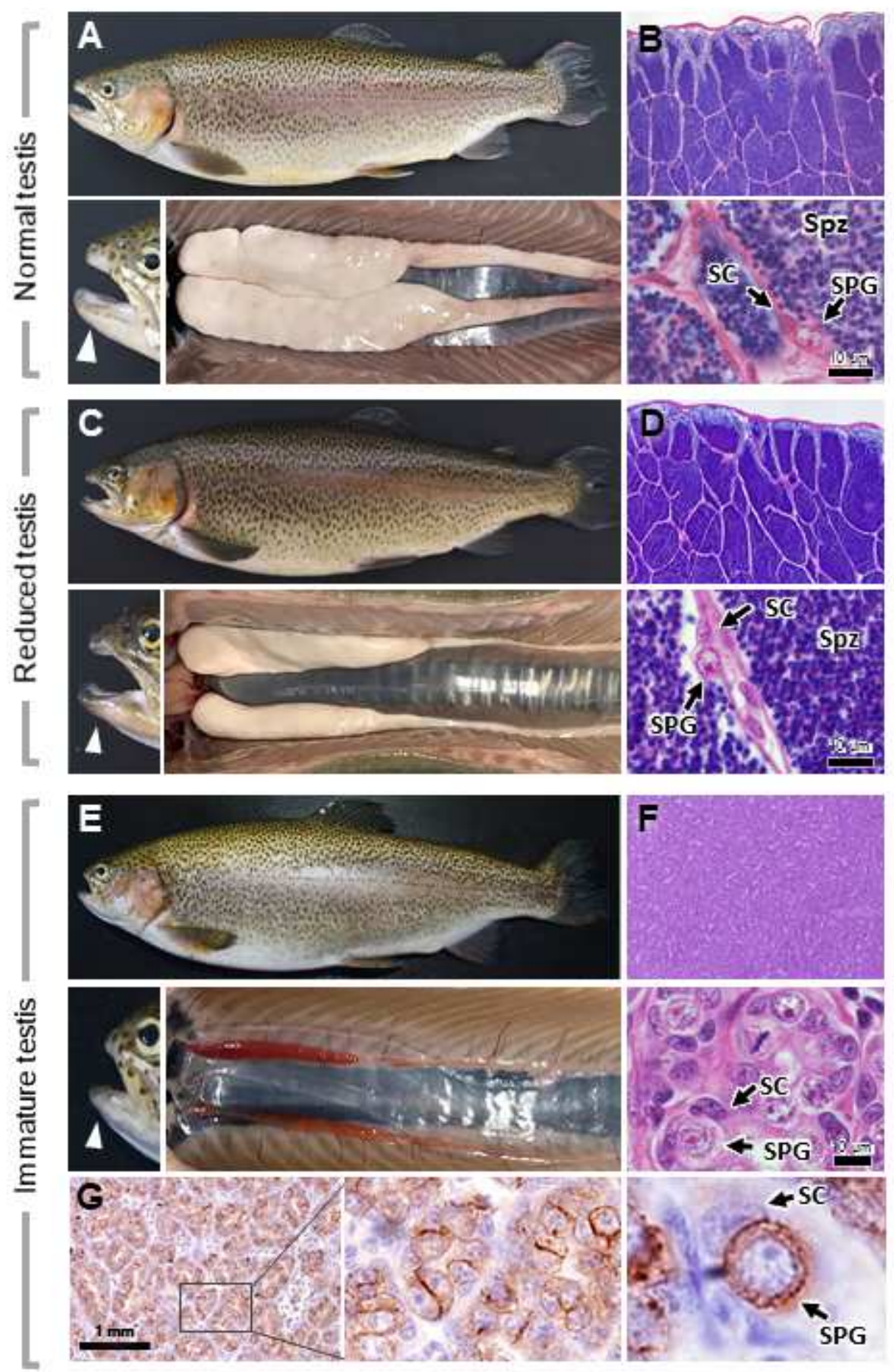

\section{Figure 2}

External body appearance and morpho-histological analysis of gonads in warm and control temperature males. (A-B) Adult trout with typical male phenotype presenting a hook-like jaw, a large whitish testis with abundant spermatozoa; spermatogonia and Sertoli cells are also present. (C-D) Adult trout with typical male phenotype as in (A), but with a smaller testis; testis histology presents similar aspect to (B). (E, F) Adult trout without male-specific secondary sexual characteristics, presenting a thin, reddish gonad, without spermatozoa; most germ cells are spermatogonia. SPG: spermatogonia; CS: Sertoli cells; Spz: 
spermatozoa. Arrowheads indicate the jaw, which has a hook-like morphology in A and C (mature males), but not in $E$ (immature male). (G) Immunohistochemical detection of undifferentiated spermatogonia in immature testis with a cell surface marker.
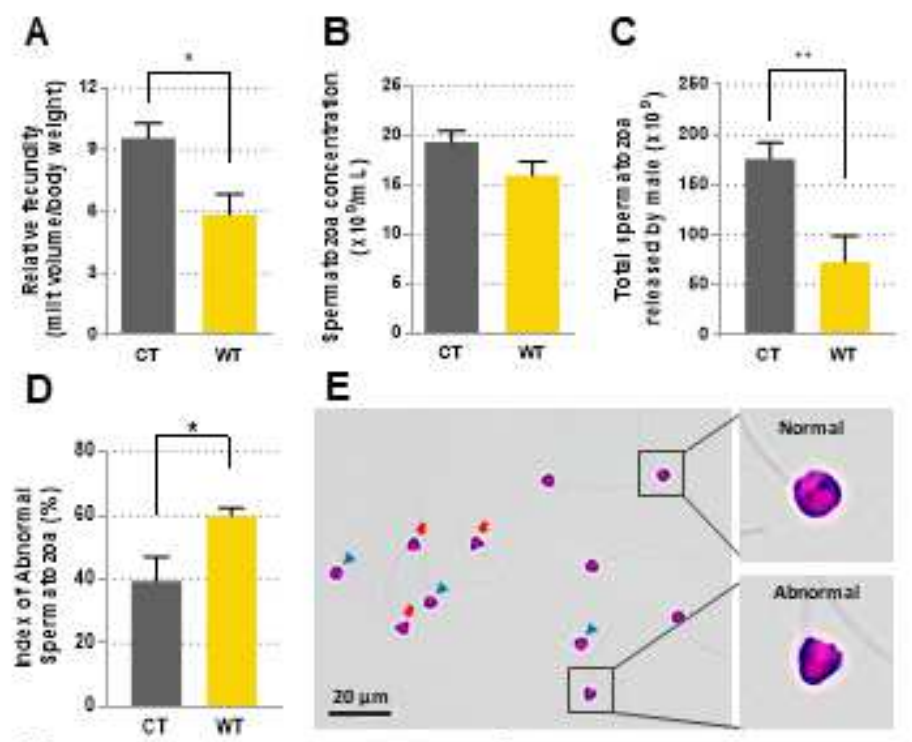

E
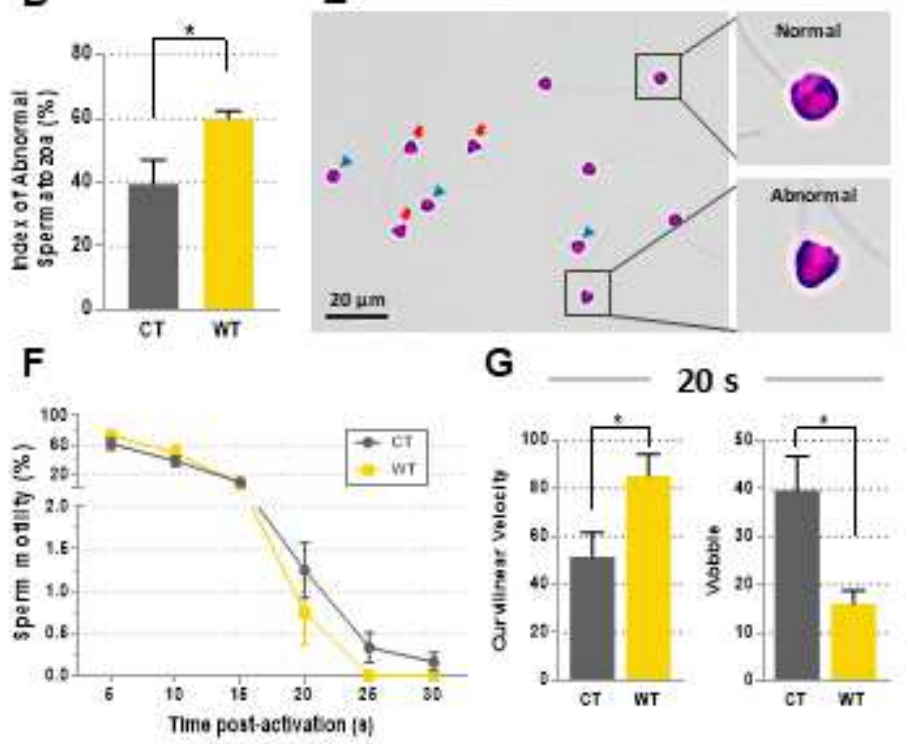

Figure 3

Fecundity of males and sperm motility parameters in control (CT) and warm (WT) temperature groups. (A) The relative fecundity was significantly lower in WT than in CT group, (B) but without differences in sperm concentration, (C) the total number of sperm released per male was significantly lower in the WT than in CT. (D-E) Morphological comparison between the percentages of spermatozoa with normal-ovoid and abnormal-triangular heads. (F) Sperm motility analyses in CT and WT males between 5 and $30 \mathrm{~s}$ post-activation. (G) Curvilinear velocity and wobble showed opposite patterns at $20 \mathrm{~s}$. Asterisks indicate significant difference for $p<0.05$. 

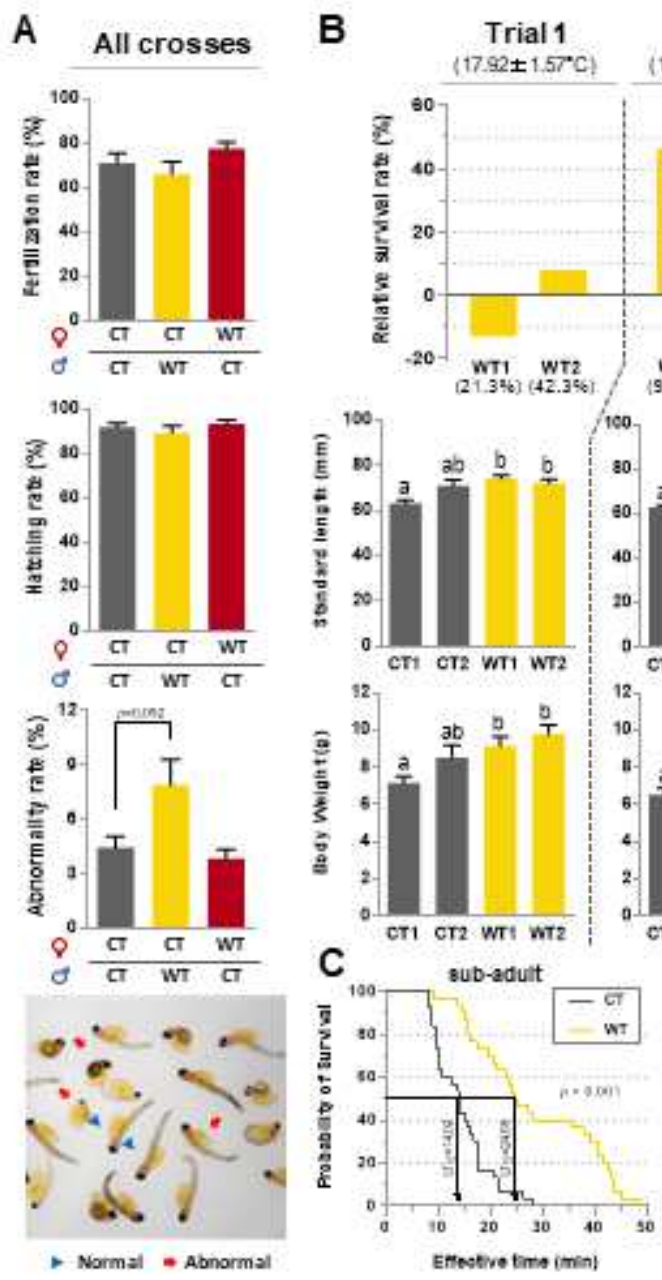

Trial 2 Trial 3 $\left(18.74 \pm 1.59^{\circ} \mathrm{C}\right) \quad\left(19.20 \pm 129^{\circ} \mathrm{C}\right)$
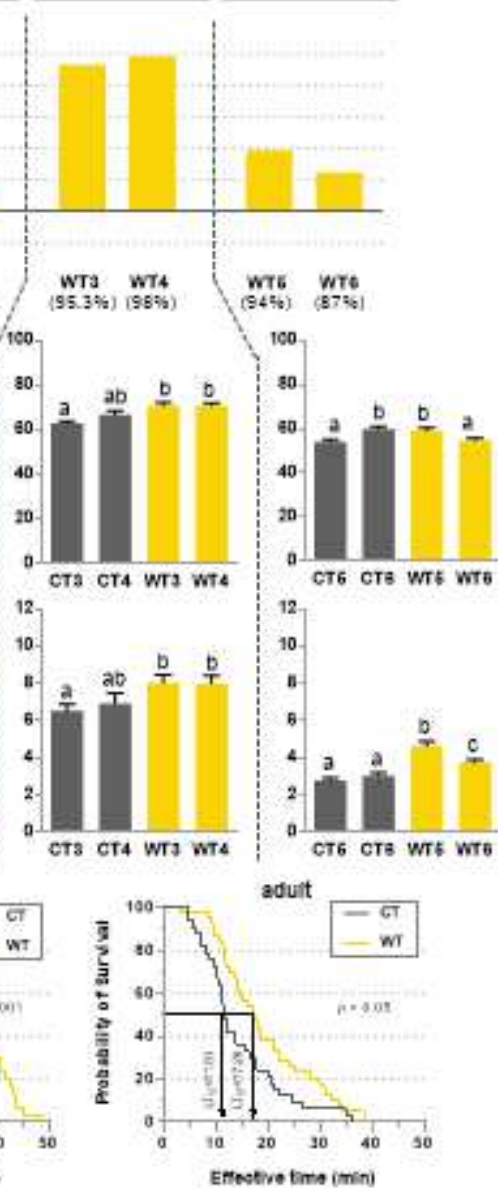

\section{Figure 4}

Fertilization, hatching, and abnormality rates of progeny produced by gametes from control (CT) and warm temperature (WT) groups (A). Rates of fertilization, hatching, and abnormality did not differ among the crosses. Crosses between CT females vs. WT males showed higher abnormality rates, with typical body deformities showed in the image just below. (B) Normalized survival rate (in relation to the average of respective CT groups) and growth parameters in F1 progeny derived from the CT/WT males submitted to warm temperature. Temperature values below each trial represent the average temperature \pm SD during challenge experiment. Numbers between brackets in the graph of survival represent the absolute survival rates for each group. (C) Comparative analysis of upper thermal tolerance using F1 sub-adults and adults from CT and WT males using effective time (ET). LT50 (median lethal temperature) values are indicated for each curve. 


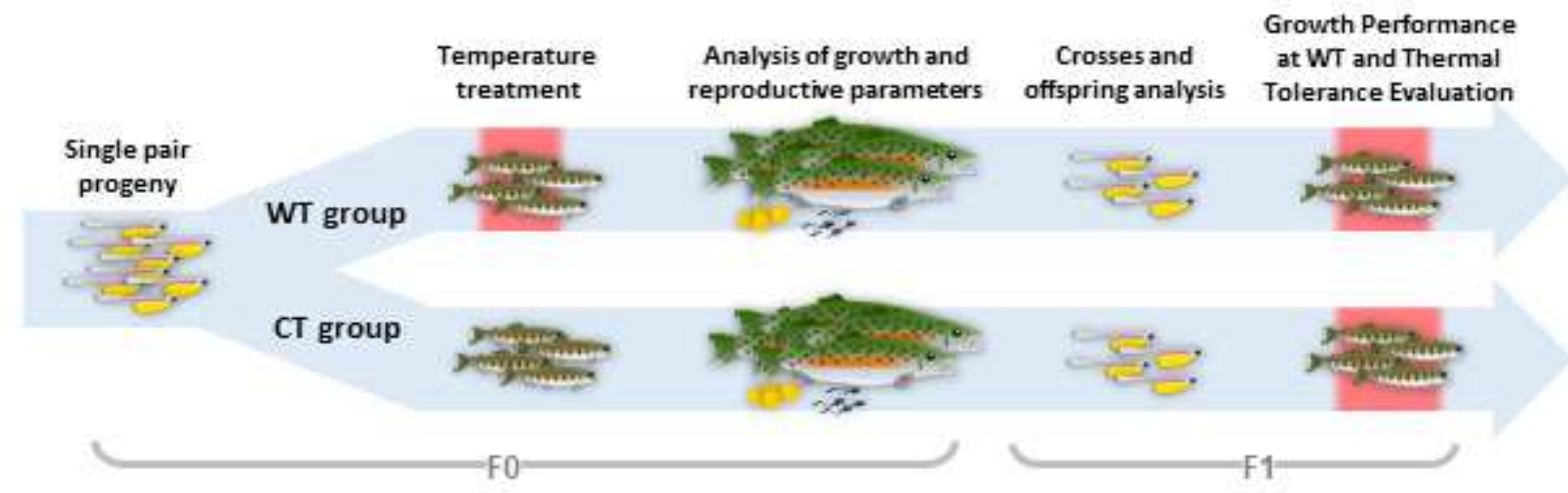

Figure 5

Overview representation of the experimental design. Rainbow trout juveniles obtained from a single pair cross were divided in two groups. At six-months, one group was exposed to warm temperature (WT) for three months in a local fish farm (Pindamonhangaba) while control group was maintained at Salmonid Experimental Station (Campos do Jordao). After this period, the treated group returned to control temperature until reaching sexual maturity for the analysis of growth and reproductive parameters. Finally, survival and growth performance of respective progenies at WT and upper thermal tolerance were evaluated.

\section{Supplementary Files}

This is a list of supplementary files associated with this preprint. Click to download.

- ButzgeSuppMat.pdf 